\title{
Xe-135 Production from Cf-252
}

\section{Methods and Applications of Radioanalytical Chemistry}

\author{
C. A. McGrath \\ T. P. Houghton \\ J. K. Pfeiffer \\ R. K. Hague
}

March 2012

The INL is a

U.S. Department of Energy

National Laboratory

operated by

Battelle Energy Alliance

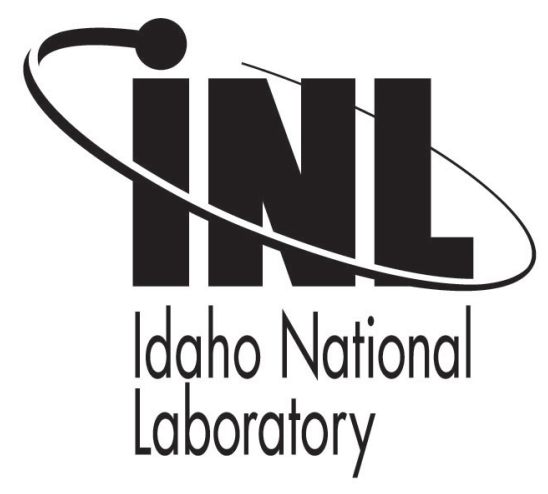

This is a preprint of a paper intended for publication in a journal or proceedings. Since changes may be made before publication, this preprint should not be cited or reproduced without permission of the author. This document was prepared as an account of work sponsored by an agency of the United States Government. Neither the United States Government nor any agency thereof, or any of their employees, makes any warranty, expressed or implied, or assumes any legal liability or responsibility for any third party's use, or the results of such use, of any information, apparatus, product or process disclosed in this report, or represents that its use by such third party would not infringe privately owned rights. The views expressed in this paper are not necessarily those of the United States Government or the sponsoring agency. 
100Log Number 396

Title: Xe-135 Production from Cf-252

Authors: C. A. McGrath, T. P. Houghton, J. K. Pfeiffer, R. K. Hague

Postal Address of each Author:

C. A. McGrath, T. P. Houghton, J. K. Pfeiffer, R. K Hague

Idaho National Laboratory, P.O. Box 1625 Idaho Falls, ID 83415

Corresponding Author:

Christopher A. McGrath

e-mail address: Christopher.mcgrath@inl.gov

Phone: 208-533-8064

Fax: 208-533-7755 


\title{
Xe-135 production from $\mathrm{Cf}-252$
}

\author{
C. A McGrath, T. P. Houghton, J. K. Pfeiffer, R. K. Hague \\ Idaho National Laboratory
}

The presence of ${ }^{135} \mathrm{Xe}$ is often used as an indicator that fission has occurred, and is used to help enforce the Comprehensive Test Ban Treaty. There are no known commercial suppliers, though it can be acquired. Readily available standards of this isotope are very useful. ${ }^{135} \mathrm{Xe}$ can be produced through fission, or by neutron capture on ${ }^{134} \mathrm{Xe}$. At the INL, scientists have previously transported fission products from an electroplated ${ }^{252} \mathrm{Cf}$ thin source for the measurement of nuclear data of short-lived fission products using a technique called He-Jet collection. A similar system has been applied to the collection of gaseous ${ }^{135} \mathrm{Xe}$, and ${ }^{133} \mathrm{Xe}$, in order to produce standards of these isotopes.

\section{Introduction}

${ }^{135} \mathrm{Xe}$ is a good indicator that fission has occurred and is a valuable isotope used to help enforce the Comprehensive Test Ban Treaty. Due to its rather short half life and minimal commercial interest, there are few ways that ${ }^{135} \mathrm{Xe}$ can be purchased. Currently, calibration standards can be purchased from the University of Texas ${ }^{1}$. These standards are made by the neutron irradiation of stable Xe gas. As such they contain significant quantities of Xe carrier. Readily available carrier-free standards of this isotope with other radioactive xenon isotopes would be very useful for calibrating collection and analytical techniques. ${ }^{135} \mathrm{Xe}$ can be produced in the fissioning of actinide isotopes, or by neutron capture on ${ }^{134} \mathrm{Xe}$. Since the neutron capture cross section of ${ }^{134} \mathrm{Xe}$ is only about 265 millibarns, neutron capture is a low yield, though useful, production route.

${ }^{135} \mathrm{Xe}$ has a half life $\left(\mathrm{t}_{1 / 2}\right)$ of $9.14 \mathrm{hr}$; its cumulative yields from both thermal and fast neutron fission of ${ }^{235} \mathrm{U}$ and ${ }^{239} \mathrm{Pu}$ are $6.54 \%, 5.67 \%$ and $7.61 \%, 6.18 \%$, respectively. Its build-up is significant in clad reactor fuel. This buildup is the cause of "Xe poisoning" in nuclear reactors since it continues to increase once fission has stopped due to the $6.57 \mathrm{hr}$ half-life of the parent ${ }^{135} \mathrm{I}$. 
${ }^{135} \mathrm{Xe}$ also has one of the highest thermal neutron capture cross-sections of any isotope (approximately $2.6 \mathrm{x} 10^{6}$ b) and neutron capture reactions over longer irradiation times significantly deplete the ${ }^{135} \mathrm{Xe}$ isotope. ${ }^{135} \mathrm{Xe}$ could be best produced in a high flux reactor or a fast reactor where ${ }^{135} \mathrm{Xe}$ neutron absorption cross sections are negligible.

${ }^{135} \mathrm{Xe}$ is also produced by spontaneous fission of ${ }^{252} \mathrm{Cf}$. ${ }^{252} \mathrm{Cf}$ has a spontaneous fission rate of about $6 \times 10^{11} \mathrm{~s}$ ${ }^{1} \mathrm{~g}^{-1}$. The cumulative yield of ${ }^{135} \mathrm{Xe}$ from the spontaneous fission of ${ }^{252} \mathrm{Cf}$ is $4.19 \%$; and the competing neutron capture reaction that depletes ${ }^{135} \mathrm{Xe}$ in thermal reactor systems is negligible because the neutron capture crosssection is low for fast fission neutrons.

At the INL, scientists have previously transported fission products from an electroplated ${ }^{252} \mathrm{Cf}$ thin source for the measurement of nuclear data of short-lived fission products using a technique called He-Jet collection ${ }^{2}$. The thin film of californium provided a near 2-Pi geometry; that coupled with the thinness of the film maximized fission product release into the "jet" atmosphere. A nickel foil was used to segregate high energy ejected fission products that are not stopped in the foil from the ${ }^{252} \mathrm{Cf}$ particles that ablate from the surface of the $\mathrm{Cf}$ film due to fission. A slow helium purge loaded with $\mathrm{NaCl}$ aerosols was used to transport fission fragments.

In order to validate the idea of fission product collection, an aluminum foil was placed over a $2.07 \times 10^{5} \mathrm{~Bq}$ (10.0 ng) ${ }^{252} \mathrm{Cf}$ source that was dried (not electroplated) and after 26 days, the $\mathrm{Al}$ foil was repetitively gamma-ray counted using an HPGe detector. The gamma-ray spectrum from the first count is shown in Figure. 1. The two peaks identified are from ${ }^{135} \mathrm{Xe}$. Table 1 lists the fission product radionuclides identified in this first spectrum. As a next step, a $2 \mathrm{ng}{ }^{252} \mathrm{Cf}$ source (approximately 1200 fissions/second) was electroplated in order to study both the transmission of fission fragments through various foils and the capture of fission fragments. Figure 2 shows the fission spectra of the bare ${ }^{252} \mathrm{Cf}$ source and the same spectra after the fission fragments have passed through various thin films.

It is quite apparent that as the cover-foil thickness increases, the energy spectrum is shifted to lower energies and gradually the lower energy peak is increasingly populated. However, it is obvious that the ${ }^{252} \mathrm{Cf}$ source can be covered with a foil thickness of up to $\sim 1.8 \mathrm{mg} / \mathrm{cm}^{2}$, with most of the fission fragments being transmitted.

Four different collection techniques were originally considered for ${ }^{135} \mathrm{Xe}$.

1. Head-space gas collection over a solution

2. Foil-based collection

3. Helium-jet collection 


\section{Stagnant-volume collection}

Each of these methods has strengths and weaknesses. It is believed that all would provide success to some degree, but each has its limitations.

Head-space gas collection has probably the lowest initial overhead of the four techniques. It really only requires a properly-fitted gas-tight chamber partially-filled with a solution containing dissolved 252Cf. Over time, the $252 \mathrm{Cf}$ fissions and the non-gaseous fission products remain suspended or dissolved in the solution, while the gaseous products accumulate in the head-space gas. Ideally, the chamber would be setup to allow the use of helium to drive any gaseous products out of the solution at the time of purging. The fission-gas-loaded helium is passed through liquid-nitrogen-cooled charcoal to separate the fission gases from the helium. The Xe fission gas would then be separated using a gas-chromatographic technique that will be described later.

This technique is straightforward and has been used in other radioactive decay scenarios. Unfortunately, in this particular case it has two drawbacks that make it less than ideal:

1. It requires the regular handling of microgram quantities of $252 \mathrm{Cf}$ in solution. In fact, over time, the solution will also fill with dissolved fission products. Contamination control and dose-minimization goals make this technique not the first choice.

2. Without repeated liquid extractions, this technique is limited to the collection of gaseous fission products. With the cost of obtaining $252 \mathrm{Cf}$ and building the infrastructure to work with it, it is desirable to have the flexibility to collect other fission products in the future.

Because of these limitations, it was decided to begin the investigation using another technique, while recognizing that this technique is possible, if not perfect.

Foil-based collection is also very easy to understand, if more difficult to implement. In this case, the $252 \mathrm{Cf}$ is molecularly plated onto a metal disk and the fission products are impacted upon a metal foil. Heating the foil will release the fission gas which can be collected and separated using the previously described methods. The limitations of this technique are:

1. It requires approximately 5 micrograms of $252 \mathrm{Cf}$ plated onto a metal disk. It is possible to obtain this from ORNL, or, if necessary, to produce it in-house. 
2. The collection foil will contain all fission products and the heating necessary to drive off the fission gases will volatize other fission products and make the subsequent separation and cleanup steps more difficult.

Foil collection is a viable option, but because of the importance of providing a totally pure product, it was decided to focus initial attention elsewhere.

Helium-jet collection is similar to the foil-based collection, in that the $252 \mathrm{Cf}$ is plated onto a metal disk, but the fission products are transported away from the $252 \mathrm{Cf}$ using a helium jet. Fission gases will be transported along with the helium and, if desired, non-gaseous fission products can be transported using an aerosol like $\mathrm{KCl}$. Using pure helium will eliminate much of the volatile fission product contamination inherent within the foil-based technique, but there are still negatives:

1. Again, it requires $252 \mathrm{Cf}$ plated onto a metal disk.

2. The helium flow must continue for the entire collection time and the charcoal used to trap the ${ }^{135} \mathrm{Xe}$ must be liquid nitrogen cooled for the entire time. With the two to three day saturation period of the ${ }^{135} \mathrm{Xe}$, this is inconvenient.

Obviously, the ability to transport both gaseous and non-gaseous fission products provides the flexibility that is desired. Helium-jet collection may be the technique that is chosen, ultimately, but in the short run, a somewhat simpler method may be a better choice.

Stagnant-volume collection provides a nice compromise, with many of the good features of the previous techniques, with somewhat simpler implementation. In this method, the fission products are collected in a gas volume for the desired length of time and then helium purged through cryogenic charcoal and separated.

\section{Experimental}

Stagnant-volume collection, the technique chosen, at least for the short term, combines many of the good features of the various techniques studied. The only real complication was the need for an electroplated source containing approximately 5 micrograms of ${ }^{252} \mathrm{Cf}$. The amount californium was determined by balancing the amount of ${ }^{135} \mathrm{Xe}$ required with the difficulty in handling extremely radioactive ${ }^{252} \mathrm{Cf}$. The dose rate in air for five micrograms of ${ }^{252} \mathrm{Cf}$ is approximately $0.1 \mathrm{mSv} /$ hour $^{3}$ at 1 meter. Any more than five micrograms would be difficult to handle regularly in the laboratory. The actual source purchased from ORNL in December 2010, contained 4.4 
micrograms of ${ }^{252} \mathrm{Cf}$ electroplated in a $1.2 \mathrm{~cm}$ circle on a stiff platinum foil. Dose rates for this source have been manageable, with readings of approximately $0.1 \mathrm{mSv} / \mathrm{hr}$ at $30 \mathrm{~cm}$ in the testing apparatus and with extremity dose rates approaching $0.4 \mathrm{~Sv} / \mathrm{hr}$. Initial testing of the technique was done with a significantly smaller source produced in- house.

A chamber was designed and constructed for this technique that allows for the use of two removable ${ }^{252} \mathrm{Cf}$ sources. With an aluminum central cylinder and steel source holders, this chamber is shown in Figure 3.

In normal practice, $\mathrm{a}^{252} \mathrm{Cf}$ source is loaded into one of the end plugs under a thin $\left(<2 \mathrm{mg} / \mathrm{cm}^{2}\right)$ nickel foil. The chamber is then pressurized to approximately $30 \mathrm{psi}$. This allows the highest energy fission fragments to thermalize within three inches. After a sufficient amount of time, usually two to three days, the chamber is purged with helium through a liquid-nitrogen-cooled charcoal trap. The standard setup is shown in Figure 4.

In this photo, one can see the vacuum connection and pump used to purge the chamber; the pressure gauge; the purge line at the bottom; and the outlet at the top, from which the charcoal trap is hung. The yield of the small plated ${ }^{252} \mathrm{Cf}$ source that was used for testing was determined by measuring the fission products captured in an aluminum foil placed directly over the nickel-covered ${ }^{252} \mathrm{Cf}$. For the small test source, this yield was approximately 1100 Becquerel $(\mathrm{Bq})$ of ${ }^{135} \mathrm{Xe}$ at saturation. With the larger source, it is possible to collect in excess of ten times this activity

Figure 5 shows the separation and purification apparatus, including an Agilent gas chromatograph. Basically, the fission gas is driven off the charcoal trap with heat and through a 5 ' X 1/8" 0.085 Carbosphere 60/80 Mesh column heated to150 degrees Celsius. When the Xe gas is eluted from the column it is passed through a coil wrapped around a NaI gamma-ray detector and into a storage cylinder.

Detection and measurement of the ${ }^{135} \mathrm{Xe}$ yield and purity is accomplished using standard gamma-ray detectors. Ultimately this will transition to a Canberra LEGe detector designed specifically for lower-energy gamma rays.

\section{RESULTS AND ACCOMPLISHMENTS}

While awaiting the delivery of the larger ORNL source, Tests were performed using a small locallyproduced ${ }^{252} \mathrm{Cf}$ source that was approximately 1 nanograms. Yields to this point have plateaued at approximately $50 \%$ of the foil collection value of $1100 \mathrm{~Bq} . \mathrm{k}$ It is not possible to say, at this time, why this is not much closer to 
$100 \%$. However, with the receipt of the much larger ORNL source, it will be possible to run significantly more tests with shorter collection times. Table 2 shows the approximate yield of fission products from the new source with a 2 day collection time.

In the charcoal traps, measured before the separation and purification, all the expected fission gases are observed, as well as volatile iodine and a few possible non-gaseous contaminants decayed from gaseous precursors $\left({ }^{85 \mathrm{~m}} \mathrm{Kr},{ }^{88} \mathrm{Kr}\right.$, ${ }^{129} \mathrm{Te},{ }^{132} \mathrm{I},{ }^{133} \mathrm{I},{ }^{134} \mathrm{I},{ }^{135} \mathrm{I},{ }^{133} \mathrm{Xe},{ }^{135} \mathrm{Xe},{ }^{138} \mathrm{Xe},{ }^{138} \mathrm{Cs}$, and $\left.{ }^{139} \mathrm{Ba}\right)$.

The separation is accomplished with approximately $100 \%$ yield and appears to provide total purity. In post-separation measurements, only radioactive xenon is measured. In addition to measurements in the local facility, samples were shipped to a lower-background counting facility at another location and counted to exhaustion. No activity was measured other than radioactive xenon. As one final test, a volume of separated radioactive xenon was opened under liquid scintillation cocktail, in an attempt to measure any low-level, or long lived, activities. No evidence was seen for either. At this there is reasonable confidence that pure radioactive xenon is being produced.

\section{Conclusions}

A system was constructed which can produce pure radioactive xenon from a ${ }^{252} \mathrm{Cf}$ source. Unfortunately, because of the source, it is not possible to produce pure ${ }^{135} \mathrm{Xe}$. However, for many, if not most, applications, a known combination of ${ }^{133} \mathrm{Xe}$ and ${ }^{135} \mathrm{Xe}$ is acceptable and for some, may even be preferable. In fact, the ratio of

${ }^{133} \mathrm{Xe}$ to ${ }^{135} \mathrm{Xe}$ can be varied by changing the collection and decay times. Shorter collection times will maximize ${ }^{135} \mathrm{Xe}$.

The quantities that can be produced using this technique yield great than $10 \mathrm{kBq}$ of ${ }^{135} \mathrm{Xe}$ activity. Considering delivery times, this is more than enough for the calibration of detection instrumentation. Measurements have shown that the separation and purification process produces a pure product, uncontaminated with other fission gases. Most importantly, no evidence has been found that it is contaminated with radioactive iodine, the precursor of radioactive xenon, or with ${ }^{252} \mathrm{Cf}$. 
Figure 1. Gamma-ray spectrum of first 10,000 s count of fission products $30 \mathrm{~min}$ following end of 26 day collection from $10 \mathrm{ng}{ }^{252} \mathrm{Cf}$.

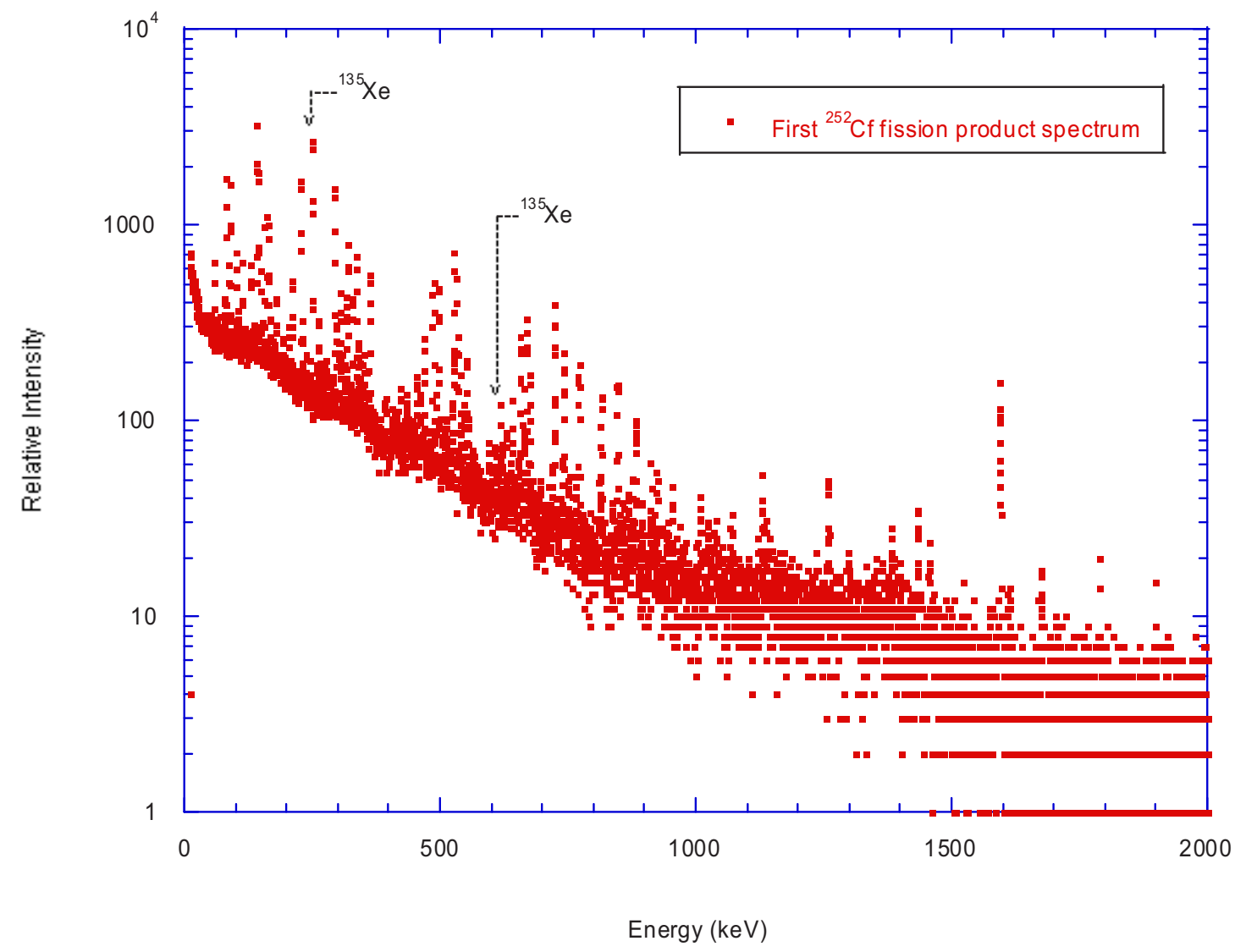

Table 1. List of observed fission products in first gamma-ray count following 26 day collection

$\begin{array}{ccccc}{ }^{83} \mathrm{Br} & { }^{99} \mathrm{Mo} & { }^{115} \mathrm{Cd} & { }^{133} \mathrm{I} & { }^{141} \mathrm{Ba} \\ { }^{92} \mathrm{Sr} & { }^{99 \mathrm{~m}} \mathrm{Tc} & { }^{115 \mathrm{~m}} \mathrm{Cd} & { }^{134} \mathrm{I} & { }^{140} \mathrm{La} \\ { }^{91 \mathrm{~m}} \mathrm{Y} & { }^{101} \mathrm{Tc} & { }^{115} \mathrm{In} & { }^{135} \mathrm{I} & { }^{142} \mathrm{La} \\ { }^{92} \mathrm{Y} & { }^{103} \mathrm{Ru} & { }^{117 \mathrm{~m}} \mathrm{Sn} & { }^{133} \mathrm{Xe} & { }^{139} \mathrm{Ce} \\ { }^{93} \mathrm{Y} & { }^{105} \mathrm{Ru} & { }^{123} \mathrm{Te} & { }^{135} \mathrm{Xe} & { }^{141} \mathrm{Ce} \\ { }^{94} \mathrm{Y} & { }^{105 \mathrm{~m}} \mathrm{Rh} & { }^{127 m} \mathrm{Te} & { }^{135 \mathrm{~m}} \mathrm{Xe} & { }^{143} \mathrm{Ce}\end{array}$




$\begin{array}{ccccc}{ }^{95} \mathrm{Y} & { }^{105} \mathrm{Rh} & { }^{131 \mathrm{~m}} \mathrm{Te} & { }^{138} \mathrm{Xe} & { }^{153} \mathrm{Sm} \\ { }^{95} \mathrm{Zr} & { }^{106} \mathrm{Ru} / \mathrm{Rh} & { }^{131} \mathrm{Te} & { }^{138} \mathrm{Cs} & { }^{152} \mathrm{Eu} \\ { }^{97} \mathrm{Zr} & { }^{109} \mathrm{Pd} & { }^{132} \mathrm{Te} & { }^{131} \mathrm{Ba} & { }^{152 \mathrm{~m}} \mathrm{Eu} \\ { }^{92 \mathrm{~m}} \mathrm{Nb} & { }^{110 \mathrm{~m}} \mathrm{Ag} & { }^{131} \mathrm{I} & { }^{139} \mathrm{Ba} & \\ { }^{97} \mathrm{Nb} & { }^{109} \mathrm{Cd} & { }^{132} \mathrm{I} & { }^{140} \mathrm{Ba} & \end{array}$

Figure $2 .{ }^{252} \mathrm{Cf}$ fission spectra for the bare source and after transmission through various thin foils

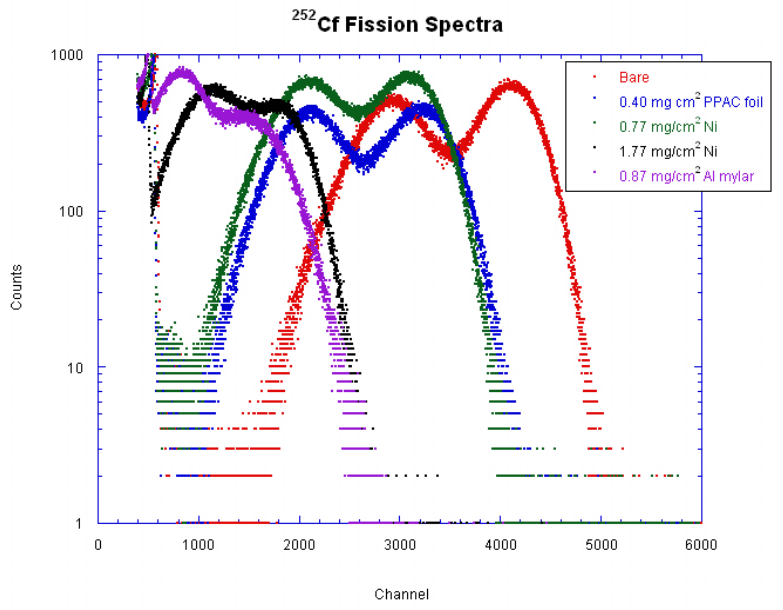

Figure 3. Photographs and drawings of the chamber constructed for stagnant-volume or helium-jet collection 


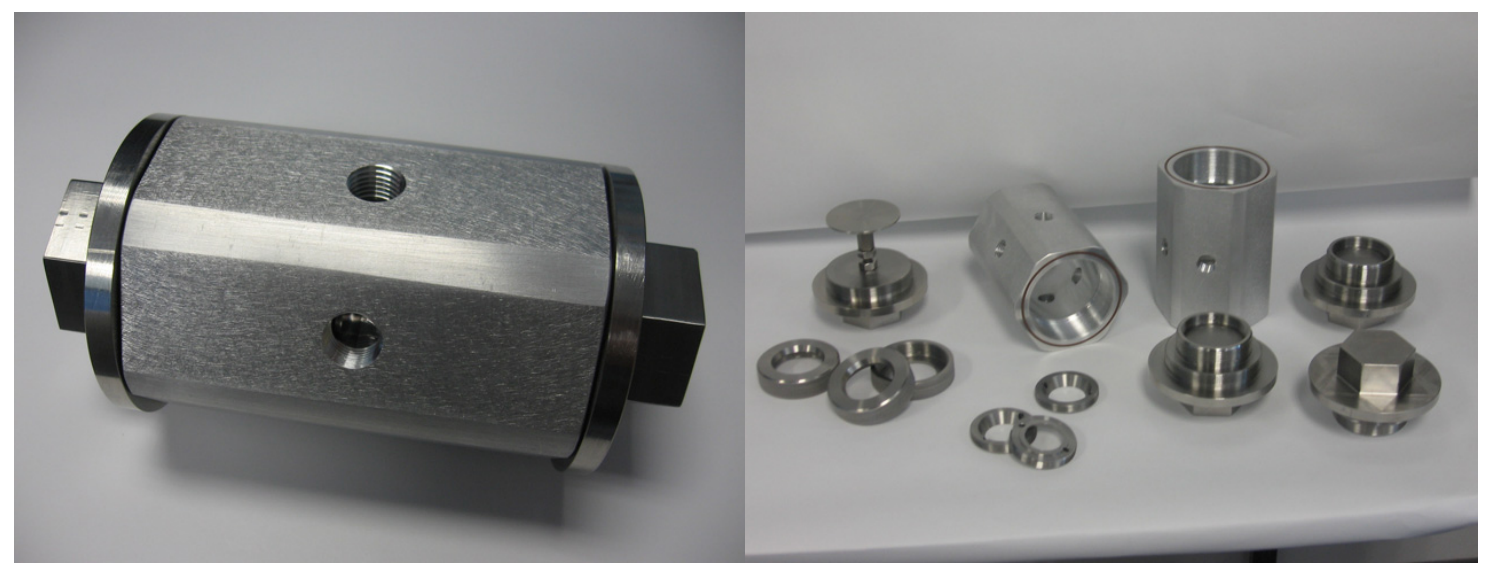

\section{Cf collection chamber dual source holder assy}

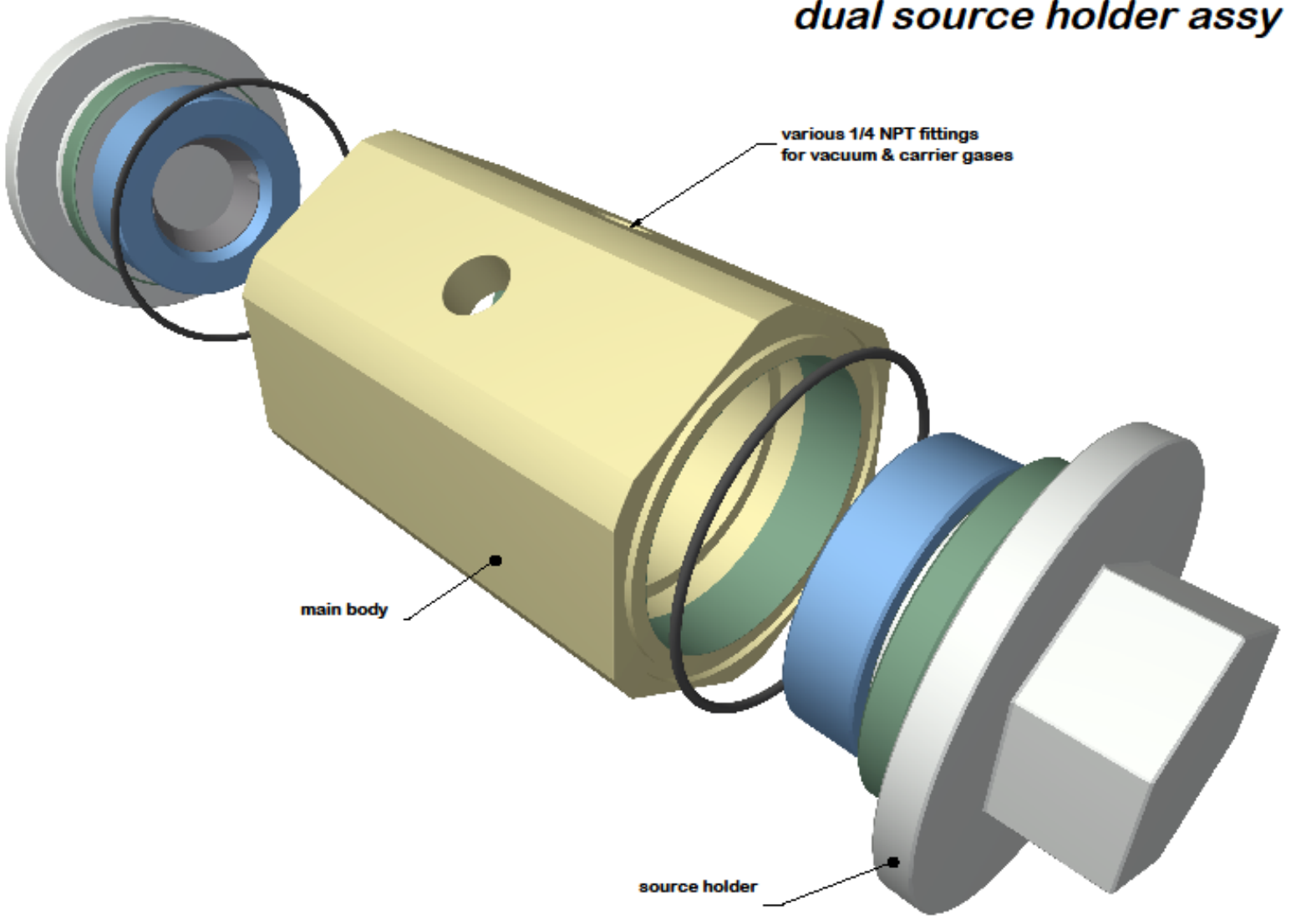

Figure 4. Photograph of the standard chamber setup for stagnant-volume collection 


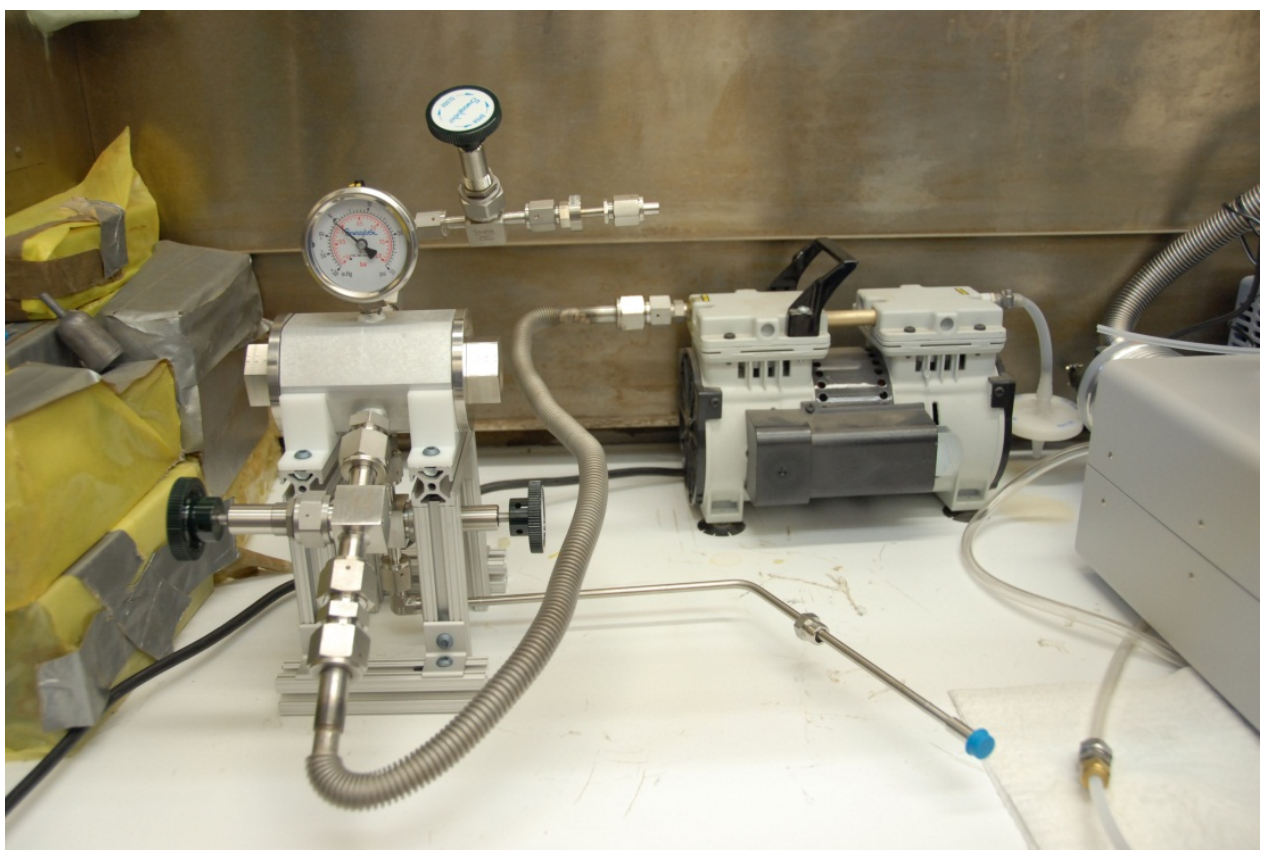

Figure 5. Photographs of the separation and purification system

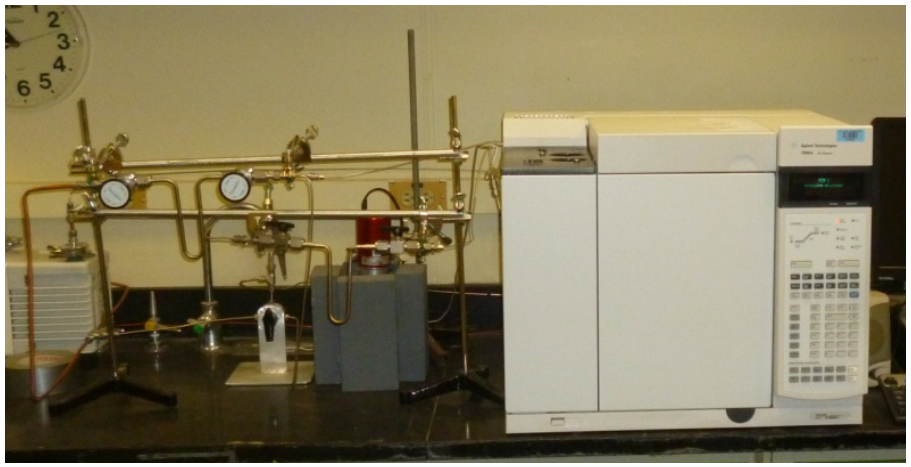




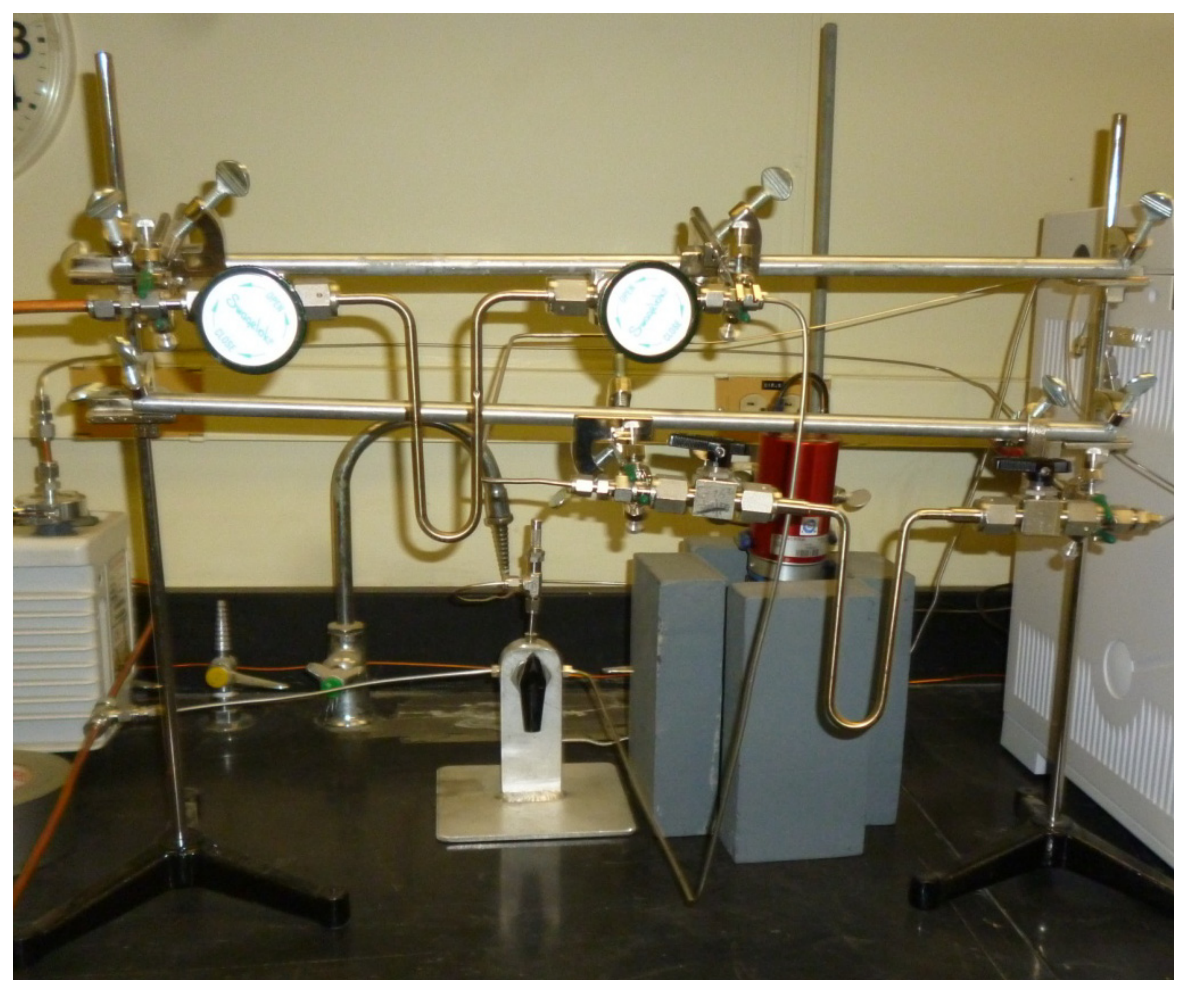

Table 2. List of significant observed fission products from the large ${ }^{252} \mathrm{Cf}$ source with a two day collection time

\begin{tabular}{|c|c|}
\hline Isotope & Activity \\
\hline${ }^{99} \mathrm{Mo}$ & $6 \mathrm{e}-1$ \\
\hline${ }^{105} \mathrm{Rh}$ & $2.9 \mathrm{e}-1$ \\
\hline${ }^{131} \mathrm{I}$ & $1.87 \mathrm{e}-2$ \\
\hline${ }^{133} \mathrm{I}$ & $1.69 \mathrm{e} 1$ \\
\hline${ }^{135} \mathrm{I}$ & $2.27 \mathrm{e}-1$ \\
\hline${ }^{135} \mathrm{Xe}$ & $2.5 \mathrm{e}-1$ \\
\hline${ }^{140} \mathrm{Ba}$ & $3.5 \mathrm{e}-2$ \\
\hline
\end{tabular}

${ }^{1}$ Hass DR, Biegalski SR, Foltz Biegalski KM, Jour. Radioanal and Nucl. Chem., (2009) 282(3): 677-680.

${ }^{2}$ Anderl RA, Novick VJ, Greenwood RC, "Basic Studies of a Gas-Jet-Coupled Ion Source for On-Line Isotope Separation", in H. L. Ravn; E. Kugler; S. Sundell, Electromagnetic isotope separators and techniques related to their 
applications : proceedings of the 10th International Conference on Electromagnetic Isotope Separators and Techniques Related to their Applications, Amsterdam: North Holland, 1981.

${ }^{3}$ Martin RC, Knauer JB, Balo PA, Appl Radiat. Isot. (2000) 53(4-5):785-92. 